\title{
Zika virus and Zika fever
}

\author{
Zhaoyang Wang, Peigang Wang ${ }^{\bowtie}$, Jing An
}

Department of Microbiology, School of Basic Medical Sciences, Chinese Capital Medical University, Beijing 100069, China

An emerging mosquito-borne arbovirus named Zika virus (ZIKV), of the family Flaviviridae and genus Flavivirus, is becoming a global health threat. ZIKV infection was long neglected due to its sporadic nature and mild symptoms. However, recently, with its rapid spread from Asia to the Americas, affecting more than 30 countries, accumulating evidences have demonstrated a close association between infant microcephaly and Zika infection in pregnant women. Here, we reviewed the virological, epidemiological, and clinical essentials of ZIKV infection.

\section{KEYWORDS Zika virus; Zika fever; Zika host interaction; microcephaly; neuronal disorder}

\section{DISCOVERY OF THE ZIKA VIRUS}

In the late 1940s, two groups of investigators that were searching primarily for the natural source of the yellow fever virus independently isolated an unrecorded virus in the Zika forest near Lake Victoria in Uganda, an East African country. The first isolation, by G. W. A. Dick, was made from the serum of a sentinel febrile rhesus monkey in April 1947. The second isolation, by S. F. Kitchen, was obtained from a batch of Aedes africanus mosquitoes in January 1948. Viruses from these two isolations were shown to be identical by the reciprocal neutralization test and it was named the Zika virus (ZIKV) (766 strain) after the forest where it was isolated (Dick et al., 1952). In a subsequent test at the same location, ZIKV neutralizing antibodies were detected in the sera of 6 of 99 humans and 1 of 15 wild monkeys (Dick, 1952).

The first isolation of ZIKV from humans was reported in 1954 in eastern Nigeria, a West African nation, where ZIKV was isolated from one of three patients that

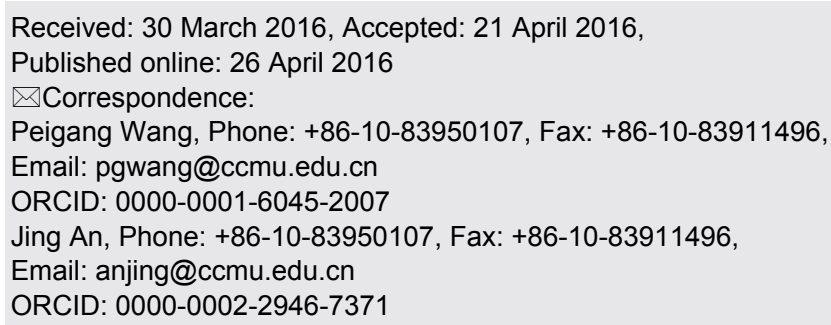

were infected during an epidemic (Macnamara, 1954). Two years later, the Eastern Nigerian strain of ZIKV was inoculated into a volunteer resulting in a mild, shortlived febrile condition without involvement of any particular tissue or viscus (Bearcroft, 1956). A study in the late 1970 s demonstrated that $40 \%$ of Nigerians had Zika virus neutralizing antibodies, showing the extensive prevalence of ZIKV infection in this country (Fagbami, 1979).

\section{RAPID SPREAD OF ZIKV IN RECENT YEARS}

Since the discovery of ZIKV, several outbreaks have been reported in tropical Africa and in some areas of Southeast Asia. In 1954, neutralizing antibodies specific to ZIKV were detected in $16.8 \%$ of human sera obtained from various districts throughout India, but no documented cases of infection were reported (Smithburn et al., 1954).

In 1977-1978, ZIKV infection was considered to be the cause of fever in Indonesia (Olson et al., 1981). However, the first major epidemic of Zika fever was reported in 2007 in the Yap Islands of the Federated States of Micronesia, in which 185 cases were confirmed, but without severe morbidity or mortality (Duffy et al., 2009). The origin of ZIKV on Yap Island remains unclear, but it was likely introduced through infected humans or mosquitoes. Phylogenetic research conducted by Haddow et al. (2012) to clarify the genetic relationship 
among geographically different ZIKV strains and the origin of the strains responsible for the 2007 outbreak on Yap Island consolidated the previous epidemiological evidence that the EC Yap strain, an isolate determined by epidemic consensus (EC) from the viral RNA of four patients, originated in Southeast Asia. This conclusion was further corroborated by the geographical proximity of Yap Island to Indonesia and Malaysia (known ZIKV affected areas).

Before the outbreak on Yap Island, only 14 human cases of ZIKV infection had ever been reported. However, ZIKV has since spread rapidly throughout South and Central America. In 2013, French Polynesia confronted a large epidemic of Zika fever, which was thought to be from an independent introduction of the virus from Asia rather than an extension of the Yap Island outbreak (Gatherer and Kohl, 2016). In February 2014, ZIKV appeared in the Western Hemisphere. One year later, Brazilian authorities officially acknowledged the first 16 Zika fever cases in its 14 states, and by the end of 2015 ZIKV was suspected to be the cause of 4,200 possible cases of microcephaly and 29 infant deaths in this country (Heukelbach et al., 2016). In other regions, ZIKV has appeared sporadically in travelers to the United States and Europe (Dyer, 2015). In February 2016, China reported the first case imported from America (Deng et al., 2016).

On the 24th of January 2016, the World Health Organization (WHO) warned that ZIKV is likely to spread throughout the Americas because its vector, the Aedes aegypti mosquito, is found in all countries in the region, except Canada and continental Chile. At about the same time, a travel alert was issued by the United States Centers for Disease Control and Prevention advising pregnant women to postpone travel to the following countries and territories: Brazil, Colombia, El Salvador, French Guiana, Guatemala, Haiti, Honduras, Martinique, Mexico, Panama, Paraguay, Suriname, Venezuela, and the Commonwealth of Puerto Rico.

\section{CHARACTERISTICS OF ZIKV}

ZIKV belongs taxonomically to the family Flaviviridae and genus Flavivirus. It is similar to other flaviviruses, such as Japanese encephalitis, yellow fever, dengue, and West Nile viruses (Pinto Junior et al., 2015), and is phylogenetically and antigenically related to the Spondweni virus. The ZIKV genome is a single-stranded positive sense RNA molecule, $10.7 \mathrm{~kb}$ in length, consisting of two flanking noncoding regions ( $5^{\prime}$ and $\left.3^{\prime}\right)$ and a single open reading frame encoding a polyprotein (NH3-CprM-E-NS 1-NS2A-NS2B-NS3-NS4A-NS4B-NS5$\mathrm{COOH}$ ) (Cunha et al., 2016; Enfissi et al., 2016b).
ZIKV can be classified into three lineages: West African, East African, and a more distantly related Yap (Baronti et al., 2014; Berthet et al., 2014). However, it is usually restricted to two distinct lineages: African and Asian (Enfissi et al., 2016a). Compared with the Asian lineage, deletions in a potential glycosylation site (Asn-154 of the E protein) were observed in several African lineages following alignment. This variation may result from viral evolution or passaging because some of these ZIKV strains were passaged intracranially in mice. Given the importance of $\mathrm{N}$-linked glycosylation at this site for infectivity and assembly of flaviviruses, its significance in the current epidemic and associated neural disorders requires further investigation.

\section{TRANSMISSION, VECTORS, AND RESERVOIRS OF ZIKV}

Transmission of ZIKV occurs usually by a bite of infected mosquitoes from the Aedes genus, primarily $A$. aegypti in tropical regions (Figure 1). However, A. polynesiensis was the vector spreading ZIKV in the 2013 French Polynesia epidemic (Baronti et al., 2014). It remains unclear whether changes in the vector preference of ZIKV and/or differences in vectors are a reason for its rapid spread.

In addition to vector-borne transmission, ZIKV could potentially be transmitted by blood transfusion like other flaviviruses, and several affected countries have developed strategies to try and screen blood donors (Franchini and Velati, 2015; Marano et al., 2015). A remarkable feature of ZIKV is its potential sexual and vertical perinatal transmission. There have been already two cases of sexual transmission and two cases of vertical perinatal transmission reported (Besnard et al., 2014; Musso et al., 2015; Gatherer and Kohl, 2016).

ZIKV reservoirs in nature remain unclear. Some scholars indicate there is a primate reservoir, while others indicate that they have detected anti-Zika antibodies in various animals such as elephants, rodents, zebras, and orangutans (McCrae and Kirya, 1982; Darwish et al., 1983).

\section{ZIKV SUSCEPTIBLE CELLS AND POTENTIAL RECEPTORS}

Study of ZIKV was long neglected because, until the recent outbreak, the infections did not appear to be severe or to cause any unexpected effects. Thus, little is known about the life cycle of ZIKV in infected cells. Mosquitoes are capable of inoculating ZIKV into the human skin through a bite. Thus, potential target cells for this virus may be present in the epidermis and dermis, which are the first line of defense. Indeed, Hamel et al. (2015) 


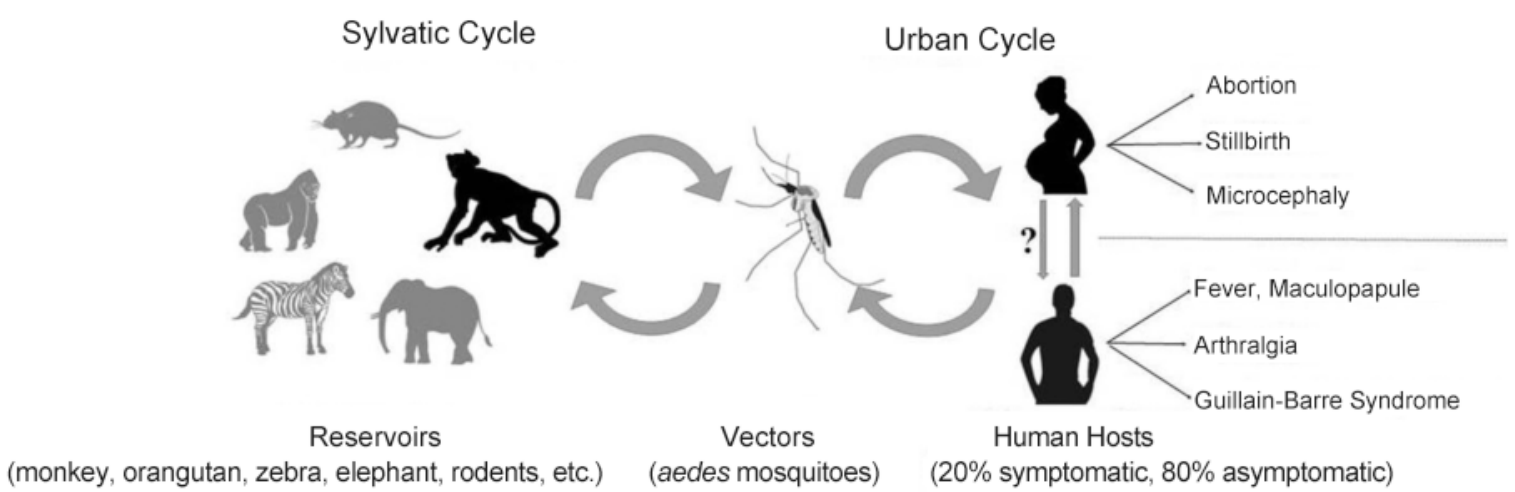

Figure 1. The transmission cycle, vectors and clinical manifestations of ZIKV. The transmission cycle of ZIKV encompasses sylvatic cycle and urban cycle. In the sylvatic cycle, rhesus monkey is a corroborated ZIKV reservoir with the reality that a live ZIKV strain has been isolated from it. It is highly suspected that orangutan, zebra, elephant, and rodent are probable ZIKV reservoirs with regard to the detection of anti-ZIKV antibody in these animals. The transmission vectors of ZIKV are Aedes mosquitoes, especially Aedes albopictus and Aedes aegypti. Sexual transmission of ZIKV has been suggested, though currently, the cases are all involved in transmission from infected males to females. Most human infections (up to $80 \%$ ) are asymptomatic, and in the apparently presented Zika cases, fever, maculopapule, arthralgia, and even complications such as GBS and microcephaly are reported.

used human permissive cells to demonstrate receptors for ZIKV entry and viral-host interaction. Specifically, these authors found that skin cells, including immature dendritic cells, epidermal keratinocytes, and dermal fibroblasts, were all permissive for ZIKV infection. In epidermal keratinocytes, the presence of pyknotic nuclei in the stratum granulosum and the appearance of cytoplasmic vacuolization were found following inoculation of ZIKV, indicating apoptosis in these cells. In skin fibroblasts, high RNA copy numbers were detected rapidly upon ZIKV infection, and a gradual increase in the production of nascent viral particles was observed over time, implying active viral replication in these cells. The presence of apoptosis was similar to observations made with dengue virus that induced apoptosis in infected human epidermis explants (Limon-Flores et al., 2005; Hamel et al., 2015). However, because monocytes rather than fibroblasts and keratinocytes are the major target cells for dengue virus in vivo, their contribution during ZIKV infection requires further validation.

Neural progenitor cells (NPCs) are precursors from which neurons are produced. In addition to fibroblasts, NPCs are target cells for ZIKV (Tang et al., 2016). Mounting evidence has defined the causal relationship between microcephaly and ZIKV infection. However, there were no direct experimental studies confirming this relationship until the appearance of data that NPCs can be directly targeted by ZIKV. Specifically, Tang et al. (2016) corroborated that ZIKV could efficiently infect NPCs in vitro and that the infected cells could release a large number of infectious ZIKV particles. Additionally, ZIKV infection induced NPC apoptosis and cell cycle dysregulation. These effects ultimately reduced the NPC population during cerebrum development thereby decreasing the number of neurons in the developing fetal brain.

Using the mice lacking the interferon receptor (Ifnar ${ }^{-1}$ ), Lazear et al.(2016) established a ZIKV infection animal model which developed neurological disease and succumbed to infection. High viral loads were detected in the brain, spinal cord and testes of Ifnar $1^{--}$mice, consistent not only with evidence that ZIKV causes neurodevelopmental defects in human fetuses, but also with potential sexual transmission of ZIKV.

Hamel et al. (2015) tested some entry and/or adhesion factors, that are crucial for flavivirus entry, for their capacity to mediate the entry of ZIKV. These researchers found that the TAM receptor, AXL, dendritic cell-specific intracellular adhesion molecule 3-grabbing nonintegrin (DC-SIGN or CD209), Tyro3, and, to a lesser extent, TIM-1, permitted ZIKV entry. Among the factors tested, AXL is likely to play a major role in ZIKV infection, which shows strong expression in ZIKV susceptible cells and tissues in vivo, including human radial glial cells, astrocytes, endothelial cells, and microglia in developing human cortex and by progenitor cells in developing retina (Nowakowski et al., 2016).

\section{INNATE IMMUNITY INDUCED BY ZIKV INFECTION}

By analyzing the expression profile of antiviral genes, it has been demonstrated that ZIKV induced an innate antiviral response in primary human fibroblasts at early time points following infection (Hamel et al., 2015). As soon as 6 hours post infection (hpi), the expression of pattern of recognition receptors including TLR3, MDA5, and 
RIG-I was upregulated in ZIKV-infected fibroblasts, with maximum mRNA levels detected at 48 hpi. Knockdown of TLR 3 by siRNA in HFF1 cells caused a sharp augmentation of viral RNA copy number $48 \mathrm{hpi}$. This indicated that the recognition of viral pathogen-associated molecular patterns by TLR3 and other pattern recognition receptors initiated downstream signaling pathways that enhanced the innate antiviral reaction.

Type I and type II interferons (IFNs) are able to inhibit ZIKV replication in skin fibroblasts. In ZIKV-infected fibroblast, mRNA levels of IRF7 are also increased. IRF7 is a transcription factor that binds to the IFN-stimulated response element (Honda et al., 2005). Thus, increase in IRF7 controls not only the upregulation of a set of IFN-stimulated genes such as OAS2, ISG15, and MX1, but also the increased IFN- $\alpha$ and IFN- $\beta$ detected following ZIKV infection.

Type III interferon has been recently shown to be an important factor for ZIKV protection. Upon ZIKV infection in pregnant women, type III interferon (IFN $\lambda 1$ ) is constitutively released by primary human trophoblast cells and functions in both a paracrine and autocrine manner to protect trophoblast and non-trophoblast cells from ZIKV infection. However, the mechanism or pathway through which ZIKV evades restriction by trophoblast-derived IFN $\lambda 1$ and accesses the fetal compartment to cause microcephaly is yet unknown (Bayer et al., 2016).

\section{CLINICAL MANIFESTATIONS AND COMPLICATIONS OF ZIKV INFECTION}

Symptoms caused by ZIKV infection resemble those of other flavivirus infections such as dengue fever, but are milder in form and usually last only four to seven days. Most cases $(60 \%-80 \%)$ are asymptomatic. When present, the main clinical symptoms are low-grade fever, conjunctivitis, transient arthritis/joint pain (mainly in the smaller joints of the hands and feet), a maculopapular rash that often starts on the face and then spreads throughout the body (Musso et al., 2014), and frequently pruritic, vertigo, myalgia, and digestive disorders. Neither severe presentation nor death has been reported with ZIKV infection. However, ZIKV infection can be associated with neuronal disorders such as GuillainBarré syndrome (Cao-Lormeau et al., 2016; Fauci and Morens, 2016). The clinical manifestations of ZIKV infection are similar to those of other arboviruses (e.g. chikungunya, dengue) leading to diagnostic challenges. However, because Zika fever features edema of the extremities, a unique maculopapular rash, and conjunctivitis (positive symptoms), and is also characterized by the absence of hepatomegaly, leukopenia, or hemorrhage, symptomatic diagnosis is still valuable and important.
The most severe problem caused by ZIKV infection appears to be microcephaly in a developing fetus. Conventionally, microcephaly has a low incidence rate and is usually caused by infections in early pregnancy, exposure to toxins or heavy metals, as well as genetic aberrations like Down Syndrome. However, during the ZIKV outbreak in Brazil last year, there was a sharp increase in the incidence of infants born with microcephaly in this country. The average rate of microcephaly over the previous five years in Brazil was 163 cases per year but there were over 4200 cases in 2015 , leading to the initial connection with ZIKV infection (Faria et al., 2016). In a retrospective study focusing on the association between microcephaly and ZIKV infection in French Polynesia in 2013-15, it was found that the risk of microcephaly associated with Zika virus infection was 95 cases (34-191) per 10000 women infected in the first trimester, while the baseline prevalence of microcephaly in the same regions was two cases $(95 \%$ CI $0-8)$ per 10000 neonates, implying that the risk of microcephaly in fetuses and neonates whose mothers are infected with Zika virus increases 50 folds (Cauchemez et al., 2016).

ZIKV has been detected by electronic microscopy in neural cells from fetuses with microcephaly. This suggested that a transplacental infection of the fetus may lead to microcephaly and other forms of brain damage (Oliveira Melo et al., 2016). In February 2016, Mlakar et al. (2016) reported genetic and electron-microscopic data for a pregnant European woman who was infected with ZIKV at 13 weeks of gestation while working in Brazil. In this case, microcephaly with calcifications in the fetal brain and placenta were revealed by ultrasonography performed at 29 weeks of gestation. By performing a fetal autopsy after termination of the pregnancy as requested by the mother, ZIKV was observed in the fetal brain by electron microscopy and validated by the reverse transcription polymerase chain reaction (RT-PCR) assay (Mlakar et al., 2016; Rubin et al., 2016). These results strengthened the association between ZIKV infection and microcephaly.

\section{DIAGNOSIS, TREATMENT, AND PROPHYLAXIS OF ZIKV INFECTION}

As noted above, diagnosing Zika fever based solely on the clinical presentation is difficult because of the similarity of its symptomology with other arboviruses that are endemic to similar areas (Fauci and Morens, 2016). ZIKV can be identified by RT-PCR, which specifically detects its genomic RNA in acutely ill patients. Although the period of viremia is very short, the period during which viral particles may be found in the saliva and urine is longer (Gourinat et al., 2015; de et al., 2016). The 
WHO recommends RT-PCR testing be done on serum collected within 1 to 3 days of symptom onset, or on saliva or urine samples collected during the first 3 to 5 days. One to 2 weeks later, serological detection of ZIKV specific IgM and IgG antibodies can also be performed. IgM is detectable within 3 days of the onset of illness (Hayes, 2009), but serological cross-reactions with closely related flaviviruses, such as dengue virus and West Nile virus, as well as following vaccination to other flaviviruses, are possible (Faye et al., 2008; Lanciotti et al., 2008). These limitations may be overcome when highly specific commercial Zika diagnostic kits are available.

Because ZIKV was not well-studied until the major outbreak in 2015, neither specific antiviral treatments nor an effective Zika vaccine are yet available (Ioos et al., 2014). The protective effect of interferon on ZIKV infection found in vitro (Hamel et al., 2015) has not been verified in animals or humans in vivo. At the current time, the most effective method to prevent Zika fever is vector control programmes. Current treatment for Zika fever is limited to supportive care including treatments to minimize pain, fever, and itching. Aspirin and other non-steroidal anti-inflammatory drugs are not advised to treat Zika fever because of the known potential of these drugs to elicit the hemorrhagic syndrome when used for treating other flaviviruses. For pregnant women, it is best to avoid any risk of infection because, once infected, there is little that can be done beyond supportive care (Petersen et al., 2016).

Anyone who has not been exposed to ZIKV is susceptible to infection. Currently, it is not known whether patients develop effective immunity against a second ZIKV assault. Further researches on the basic immunology and virology of ZIKV will improve our understanding of Zika fever and facilitate the development of more effective preventative and treatment measures.

\section{CONCLUSION}

ZIKV, an emerging flavivirus, was not deemed to be a formidable threat to global public health due to the purportedly mild ailment it causes. However, with the recent spread of ZIKV infection throughout the world, the potential for this virus to induce a serious set of neural disorders has become evident. To date, we have very sparse knowledge of the basic virology and immunology of ZIKV, and as a result, there is minimal information on specific prophylaxis and treatment of Zika fever. The ever-neglected ZIKV has proven its capacity to bring a global plague to mankind. Thus, in order to properly and effectively tackle the Zika plague, we should first carry out vector control programmes that have been proven to be very cost-effective means to halt the Zika epidemic
(Benelli and Mehlhorn, 2016). Vaccine development should also be emphasized. Finally, additional basic researches on ZKIV and Zika fever are needed to improve our understanding of the physiologic and molecular pathology of this virus, and enable the rapid development of a vaccine and antiviral treatments.

\section{ACKNOWLEDGMENTS}

This work was supported by the National Natural Science Foundations of China (81471957, 81271839, 81372935, 81301435, and 81401676).

\section{COMPLIANCE WITH ETHICS GUIDELINES}

This article does not contain any studies with human or animal subjects performed by any of the authors. All authors declare that they have no competing interests.

\section{REFERENCES}

Baronti C, Piorkowski G, Charrel RN, Boubis L, Leparc-Goffart I, de Lamballerie X. 2014. Complete coding sequence of zika virus from a French polynesia outbreak in 2013. Genome Announc, doi:10.1128/genome A.00500-14.

Bayer A, Lennemann NJ, Ouyang Y, Bramley JC, Morosky S, Marques ET, Jr., Cherry S, Sadovsky Y, Coyne CB. 2016. Type III Interferons Produced by Human Placental Trophoblasts Confer Protection against Zika Virus Infection. Cell Host Microbe. doi: 10.1016/j.chom.2016.03.008.

Bearcroft WG. 1956. Zika virus infection experimentally induced in a human volunteer. Trans R Soc Trop Med Hyg, 50: 442448.

Benelli G, Mehlhorn H. 2016. Declining malaria, rising of dengue and Zika virus: insights for mosquito vector control. Parasitol Res. doi: 10.1007/s00436-016-4971-z.

Berthet N, Nakoune E, Kamgang B, Selekon B, Descorps-Declere S, Gessain A, Manuguerra JC, Kazanji M. 2014. Molecular characterization of three Zika flaviviruses obtained from sylvatic mosquitoes in the Central African Republic. Vector Borne Zoonotic Dis, 14: 862-865.

Besnard M, Lastere S, Teissier A, Cao-Lormeau V, Musso D. 2014. Evidence of perinatal transmission of Zika virus, French Polynesia, December 2013 and February 2014. Euro Surveill, 19. pii: 20751

Cao-Lormeau VM, Blake A, Mons S, Lastere S, Roche C, Vanhomwegen J, Dub T, Baudouin L, Teissier A, Larre P, Vial AL, Decam C, Choumet V, Halstead SK, Willison HJ, Musset L, Manuguerra JC, Despres P, Fournier E, Mallet HP, Musso D, Fontanet A, Neil J, Ghawche F. 2016. Guillain-Barre Syndrome outbreak associated with Zika virus infection in French Polynesia: a case-control study. Lancet. doi: 10.1016/S01406736(16)00562-6.

Cauchemez S, Besnard M, Bompard P, Dub T, Guillemette-Artur P, Eyrolle-Guignot D, Salje H, Van Kerkhove MD, Abadie V, Garel C, Fontanet A, Mallet HP. 2016. Association between Zika virus and microcephaly in French Polynesia, 2013-15: a retrospective study. Lancet. doi: 10.1016/S0140-6736(16)00651-6.

Cunha MS, Esposito DL, Rocco IM, Maeda AY, Vasami FG, Nogueira JS, de Souza RP, Suzuki A, Addas-Carvalho M, Bar- 
jas-Castro Mde L, Resende MR, Stucchi RS, Boin Ide F, Katz G, Angerami RN, da Fonseca BA. 2016. First Complete Genome Sequence of Zika Virus (Flaviviridae, Flavivirus) from an Autochthonous Transmission in Brazil. Genome Announc, doi: 10.1128/genome A.00032-16.

Darwish MA, Hoogstraal H, Roberts TJ, Ahmed IP, Omar F. 1983. A sero-epidemiological survey for certain arboviruses (Togaviridae) in Pakistan. Trans R Soc Trop Med Hyg, 77: 442-445.

de MCR, Cirne-Santos C, Meira GL, Santos LL, de Meneses MD, Friedrich J, Jansen S, Ribeiro MS, da Cruz IC, Schmidt-Chanasit J, Ferreira DF. 2016. Prolonged detection of Zika virus RNA in urine samples during the ongoing Zika virus epidemic in Brazil. J Clin Virol, 77: 69-70.

Deng YQ, Zhao H, Li XF, Zhang NN, Liu ZY, Jiang T, Gu DY, Shi L, He JA, Wang HJ, Sun ZZ, Ye Q, Xie DY, Cao WC, Qin CF. 2016. Isolation, identification and genomic characterization of the Asian lineage Zika virus imported to China. Sci China Life Sci. 59:428-430.

Dick GW. 1952. Zika virus. II. Pathogenicity and physical properties. Trans R Soc Trop Med Hyg, 46: 521-534.

Dick GW, Kitchen SF, Haddow AJ. 1952. Zika virus. I. Isolations and serological specificity. Trans R Soc Trop Med Hyg, 46: 509-520.

Duffy MR, Chen TH, Hancock WT, Powers AM, Kool JL, Lanciotti RS, Pretrick M, Marfel M, Holzbauer S, Dubray C, Guillaumot L, Griggs A, Bel M, Lambert AJ, Laven J, Kosoy O, Panella A, Biggerstaff BJ, Fischer M, Hayes EB. 2009. Zika virus outbreak on Yap Island, Federated States of Micronesia. N Engl J Med, 360: 2536-2543.

Dyer O. 2015. Zika virus spreads across Americas as concerns mount over birth defects. BMJ, 351: h6983.

Enfissi A, Codrington J, Roosblad J, Kazanji M, Rousset D. 2016a. Zika virus genome from the Americas. Lancet. doi: 10.1016/S0140-6736(16)00003-9.

Enfissi A, Codrington J, Roosblad J, Kazanji M, Rousset D. 2016b. Zika virus genome from the Americas. Lancet, 387: 227-228.

Fagbami AH. 1979. Zika virus infections in Nigeria: virological and seroepidemiological investigations in Oyo State. J Hyg (Lond), 83: 213-219.

Faria NR, Azevedo Rdo S, Kraemer MU, Souza R, Cunha MS, Hill SC, Theze J, Bonsall MB, Bowden TA, Rissanen I, Rocco IM, Nogueira JS, Maeda AY, Vasami FG, Macedo FL, Suzuki A, Rodrigues SG, Cruz AC, Nunes BT, Medeiros DB, Rodrigues DS, Nunes Queiroz AL, da Silva EV, Henriques DF, Travassos da Rosa ES, de Oliveira CS, Martins LC, Vasconcelos HB, Casseb LM, Simith Dde B, Messina JP, Abade L, Lourenco J, Alcantara LC, de Lima MM, Giovanetti M, Hay SI, de Oliveira RS, Lemos Pda S, de Oliveira LF, de Lima CP, da Silva SP, de Vasconcelos JM, Franco L, Cardoso JF, Vianez-Junior JL, Mir D, Bello G, Delatorre E, Khan K, Creatore M, Coelho GE, de Oliveira WK, Tesh R, Pybus OG, Nunes MR, Vasconcelos PF. 2016. Zika virus in the Americas: Early epidemiological and genetic findings. Science, 352: 345-349.

Fauci AS, Morens DM. 2016. Zika Virus in the Americas - Yet Another Arbovirus Threat. N Engl J Med. 374:601-604.

Faye O, Dupressoir A, Weidmann M, Ndiaye M, Alpha Sall A. 2008. One-step RT-PCR for detection of Zika virus. J Clin Virol, 43: 96-101.

Franchini M, Velati C. 2015. Blood safety and zoonotic emerging pathogens: now it's the turn of Zika virus! Blood Transfus: 1 .

Gatherer D, Kohl A. 2016. Zika virus: a previously slow pandemic spreads rapidly through the Americas. J Gen Virol, 97: 269-
273.

Gourinat AC, O'Connor O, Calvez E, Goarant C, DupontRouzeyrol M. 2015. Detection of Zika virus in urine. Emerg Infect Dis, 21: 84-86.

Haddow AD, Schuh AJ, Yasuda CY, Kasper MR, Heang V, Huy R, Guzman H, Tesh RB, Weaver SC. 2012. Genetic characterization of Zika virus strains: geographic expansion of the Asian lineage. PLoS Negl Trop Dis, 6: e1477.

Hamel R, Dejarnac O, Wichit S, Ekchariyawat P, Neyret A, Luplertlop N, Perera-Lecoin M, Surasombatpattana P, Talignani L, Thomas F, Cao-Lormeau VM, Choumet V, Briant L, Despres P, Amara A, Yssel H, Misse D. 2015. Biology of Zika Virus Infection in Human Skin Cells. J Virol, 89: 8880-8896.

Hayes EB. 2009. Zika virus outside Africa. Emerg Infect Dis, 15: 1347-1350.

Heukelbach J, Alencar CH, Kelvin AA, De Oliveira WK, Pamplona de Goes Cavalcanti L. 2016. Zika virus outbreak in Brazil. J Infect Dev Ctries, 10: 116-120.

Honda K, Yanai H, Negishi H, Asagiri M, Sato M, Mizutani T, Shimada N, Ohba Y, Takaoka A, Yoshida N, Taniguchi T. 2005. IRF-7 is the master regulator of type-I interferon-dependent immune responses. Nature, 434: 772-777.

Ioos S, Mallet HP, Leparc Goffart I, Gauthier V, Cardoso T, Herida M. 2014. Current Zika virus epidemiology and recent epidemics. Med Mal Infect, 44: 302-307.

Lanciotti RS, Kosoy OL, Laven JJ, Velez JO, Lambert AJ, Johnson AJ, Stanfield SM, Duffy MR. 2008. Genetic and serologic properties of Zika virus associated with an epidemic, Yap State, Micronesia, 2007. Emerg Infect Dis, 14: 1232-1239.

Lazear HM, Govero J, Smith AM, Platt DJ, Fernandez E, Miner JJ, Diamond MS. 2016. A Mouse Model of Zika Virus Pathogenesis. Cell Host Microbe. doi: 10.1016/j.chom.2016.03.010.

Limon-Flores AY, Perez-Tapia M, Estrada-Garcia I, Vaughan G, Escobar-Gutierrez A, Calderon-Amador J, Herrera-Rodriguez SE, Brizuela-Garcia A, Heras-Chavarria M, Flores-Langarica A, Cedillo-Barron L, Flores-Romo L. 2005. Dengue virus inoculation to human skin explants: an effective approach to assess in situ the early infection and the effects on cutaneous dendritic cells. Int J Exp Pathol, 86: 323-334.

Macnamara FN. 1954. Zika virus: a report on three cases of human infection during an epidemic of jaundice in Nigeria. Trans R Soc Trop Med Hyg, 48: 139-145.

Marano G, Pupella S, Vaglio S, Liumbruno GM, Grazzini G. 2015. Zika virus and the never-ending story of emerging pathogens and transfusion medicine. Blood Transfus: 14: 95-100.

McCrae AW, Kirya BG. 1982. Yellow fever and Zika virus epizootics and enzootics in Uganda. Trans R Soc Trop Med Hyg, 76: $552-562$.

Mlakar J, Korva M, Tul N, Popovic M, Poljsak-Prijatelj M, Mraz J, Kolenc M, Resman Rus K, Vesnaver Vipotnik T, Fabjan Vodusek V, Vizjak A, Pizem J, Petrovec M, Avsic Zupanc T. 2016. Zika virus associated with microcephaly. N Engl J Med. 374:951-958.

Musso D, Nilles EJ, Cao-Lormeau VM. 2014. Rapid spread of emerging Zika virus in the Pacific area. Clin Microbiol Infect, 20: 595-596.

Musso D, Roche C, Robin E, Nhan T, Teissier A, Cao-Lormeau VM. 2015. Potential sexual transmission of Zika virus. Emerg Infect Dis, 21: 359-361.

Nowakowski TJ, Pollen AA, Di Lullo E, Sandoval-Espinosa C, Bershteyn M, Kriegstein AR. 2016. Expression Analysis Highlights AXL as a Candidate Zika Virus Entry Receptor in Neural Stem Cells. Cell Stem Cell. doi: 10.1016/j.stem.2016.03.012.

Oliveira Melo AS, Malinger G, Ximenes R, Szejnfeld PO, Alves 
Sampaio S, Bispo de Filippis AM. 2016. Zika virus intrauterine infection causes fetal brain abnormality and microcephaly: tip of the iceberg? Ultrasound Obstet Gynecol, 47: 6-7.

Olson JG, Ksiazek TG, Suhandiman, Triwibowo. 1981. Zika virus, a cause of fever in Central Java, Indonesia. Trans R Soc Trop Med Hyg, 75: 389-393.

Petersen EE, Staples JE, Meaney-Delman D, Fischer M, Ellington SR, Callaghan WM, Jamieson DJ. 2016. Interim Guidelines for Pregnant Women During a Zika Virus Outbreak - United States, 2016. MMWR Morb Mortal Wkly Rep, 65: 30-33.

Pinto Junior VL, Luz K, Parreira R, Ferrinho P. 2015. Zika Virus: A Review to Clinicians. Acta Med Port, 28: 760-765.(In Por- tuguese)

Rubin EJ, Greene MF, Baden LR. 2016. Zika Virus and Microcephaly. N Engl J Med. doi: 10.1056/NEJMe1601862.

Smithburn KC, Kerr JA, Gatne PB. 1954. Neutralizing antibodies against certain viruses in the sera of residents of India. J Immunol, 72: 248-257.

Tang H, Hammack C, Ogden SC, Wen Z, Qian X, Li Y, Yao B, Shin J, Zhang F, Lee EM, Christian KM, Didier RA, Jin P, Song H, Ming GL. 2016. Zika Virus Infects Human Cortical Neural Progenitors and Attenuates Their Growth. Cell Stem Cell. doi: 10.1016/j.stem.2016.02.016. 